The University of Southern Mississippi

The Aquila Digital Community

Faculty Publications

7-1-2007

\title{
A Multi-Scale Examination of Stopover Habitat Use by Birds
}

Jeffrey J. Buler

University of Southern Mississippi, jbuler@udel.edu

Frank R. Moore

University of Southern Mississippi, Frank.Moore@usm.edu

Stefan Woltmann

University of Southern Mississippi, Harpagus@yahoo.com

Follow this and additional works at: https://aquila.usm.edu/fac_pubs

Part of the Ecology and Evolutionary Biology Commons

\section{Recommended Citation}

Buler, J. J., Moore, F. R., Woltmann, S. (2007). A Multi-Scale Examination of Stopover Habitat Use by Birds. Ecology, 88(7), 1789-1802.

Available at: https://aquila.usm.edu/fac_pubs/8501

This Article is brought to you for free and open access by The Aquila Digital Community. It has been accepted for inclusion in Faculty Publications by an authorized administrator of The Aquila Digital Community. For more information, please contact Joshua.Cromwell@usm.edu. 


\title{
A MULTI-SCALE EXAMINATION OF STOPOVER HABITAT USE BY BIRDS
}

\author{
Jeffrey J. Buler, ${ }^{1}$ Frank R. Moore, and Stefan Woltmann ${ }^{2}$ \\ Department of Biological Sciences, University of Southern Mississippi, 118 College Dr. \#5018, Hattiesburg, Mississippi 39406 USA
}

\begin{abstract}
Most of our understanding of habitat use by migrating land birds comes from studies conducted at single, small spatial scales, which may overemphasize the importance of intrinsic habitat factors, such as food availability, in shaping migrant distributions. We believe that a multi-scale approach is essential to assess the influence of factors that control en route habitat use. We determined the relative importance of eight variables, each operating at a habitat-patch, landscape, or regional spatial scale, in explaining the differential use of hardwood forests by Nearctic-Neotropical land birds during migration. We estimated bird densities through transect surveys at sites near the Mississippi coast during spring and autumn migration within landscapes with variable amounts of hardwood forest cover. At a regional scale, migrant density increased with proximity to the coast, which was of moderate importance in explaining bird densities, probably due to constraints imposed on migrants when negotiating the Gulf of Mexico. The amount of hardwood forest cover at a landscape scale was positively correlated with arthropod abundance and had the greatest importance in explaining densities of all migrants, as a group, during spring, and of insectivorous migrants during autumn. Among landscape scales ranging from $500 \mathrm{~m}$ to $10 \mathrm{~km}$ radius, the densities of migrants were, on average, most strongly and positively related to the amount of hardwood forest cover within a $5 \mathrm{~km}$ radius. We suggest that hardwood forest cover at this scale may be an indicator of habitat quality that migrants use as a cue when landing at the end of a migratory flight. At the patch scale, direct measures of arthropod abundance and plant community composition were also important in explaining migrant densities, whereas habitat structure was of little importance. The relative amount of fleshy-fruited trees was positively related and was the most important variable explaining frugivorous migrant density during autumn. Although constraints extrinsic to habitat had a moderate role in explaining migrant distributions, our results are consistent with the view that food availability is the ultimate factor shaping the distributions of birds during stopover.
\end{abstract}

Key words: avian migration; bottomland hardwood forest; food availability; habitat selection; habitat use; landscape composition; migratory land birds; northern Gulf of Mexico; spatial scale; stopover.

\section{INTRODUCTION}

Migration is a period of exceptional energy demand, and small land bird migrants generally do not deposit enough fat to fly nonstop between breeding and wintering areas (Berthold 1975, Blem 1980). Instead, their migration is divided into alternating phases of flight and stopover, where the cumulative amount of time spent at stopover sites far exceeds time spent in flight, and largely determines the total duration of migration (Hedenström and Alerstam 1997, Alerstam 2003). When migrants stop over, they almost invariably find themselves in unfamiliar surroundings (Moore et al. 1990, Petit 2000) at a time when energy demands are

Manuscript received 7 November 2006; revised 21 December 2006; accepted 22 December 2006. Corresponding Editor: M. Wikelski.

${ }^{1}$ Present address: IAP World Services, Inc., USGS National Wetland Research Center, 147 S. Riding Blvd., Wilmington, Delaware 19808 USA.

E-mail: Jeffrey.J.Buler@iapws.com

2 Present address: Department of Ecology and Evolutionary Biology, 310 Dinwiddie Hall, Tulane University, New Orleans, Louisiana 70118 USA. likely to be high (e.g., Loria and Moore 1990). Migrants during stopover are faced with the need to acquire food in a short period of time, while balancing oftenconflicting demands between predator avoidance and food acquisition (e.g., Lindström 1990, Moore 1994, Cimprich et al. 2005), competition with other migrants and resident birds for limited resources (e.g., Moore and Wang 1991, Carpenter et al. 1993), and unfavorable weather (e.g., Gauthreaux and Belser 1999). The response by migrants to these factors, some of which are extrinsic to habitats and operate at different scales (see Hutto 1985), leads to patterns of habitat use that are scale dependent (Wiens 1989, Moore et al. 2005).

At a local scale, migrants exhibit selective use of stopover habitat (Bairlein 1983, Moore et al. 1990), and migrant distributions are often closely related to changes in food availability among and within habitats (reviewed by Moore et al. 1995). Thus, food availability is an important intrinsic habitat factor that is thought to be ultimately responsible for fine-scale habitat use patterns (Hutto 1985). Unfortunately, much of our understanding of en route habitat use comes from single, local-scale studies (reviewed by Moore and Aborn 2000), which 
may overemphasize the importance of intrinsic habitat factors. In fact, Petit (2000) concluded that factors other than food availability (e.g., energetic constraints, surrounding land use patterns) probably exert significant control over habitat use.

At a broad spatial scale, the influence of intrinsic habitat factors on habitat use gives way to that of factors extrinsic to habitat (Hutto 1985). Consider the northern Gulf of Mexico as a broad geographic region in which to view habitat selection by migrants. As birds arrive at the northern Gulf coast in spring, their energetic state and/or weather conditions constrain how far inland they travel before making landfall. For example, migrants that land on barrier islands in favorable weather are in poorer energetic condition, on average, than migrants that land after encountering opposing winds or rain over the Gulf (Moore and Kerlinger 1987, Kuenzi and Moore 1991). Additionally, radar observations reveal that adverse weather causes migrants to land in substantial numbers on the immediate coast in Louisiana (Gauthreaux 1971, Gauthreaux and Belser 1999). Consequently, habitat use patterns at this regional scale may be more closely related to proximity of habitats to the coast than to the intrinsic habitat quality per se.

At an intermediate (i.e., landscape) scale, the influence of habitat availability on habitat use by en route migrants has been recognized on theoretical grounds (Hutto 1985, Moore et al. 1995, Petit 2000) and through modeling studies (Farmer and Wiens 1998, Simons et al. 2000), but empirical support is largely lacking (but see Farmer and Parent 1997). Moreover, to study the influence of landscape-scale variables on habitat use by migrants, we must measure variables at an appropriate scale (Wiens 1989, Wiens and Milne 1989, Holland et al. 2004) to avoid incorrectly assessing the relationship between migrants and habitat use (Rukke and Midtgaard 1998, Holland et al. 2005).

A multi-scale approach is essential to assess the influence of factors that control en route habitat use (sensu O'Neill et al. 1986, Kotliar and Wiens 1990, Cushman and McGarigal 2002), but is currently lacking. Our objective was to determine the relative importance of variables, each potentially operating at a habitatpatch (e.g., food abundance and habitat composition and structure), landscape (e.g., proportion of forest cover), or regional (e.g., proximity to ecological barrier) spatial scale, in explaining the differential use of hardwood forests by Neotropical land birds during migration using multi-model inference within an information-theoretic approach. Additionally, we determined the scales at which migrants respond to landscape structure to appropriately assess the importance of forest cover at a landscape scale on habitat use patterns. Our approach involved estimating bird densities within hardwood forest habitats across landscapes with different amounts of hardwood forest cover near the Mississippi coast during spring and autumn migration.

\section{Methods}

\section{Study region and sites}

The study region, $\sim 1 \times 10^{6}$ ha in size, borders the northern coast of the Gulf of Mexico within the United States, and covers portions of nine counties of Mississippi and two parishes of Louisiana (Fig. 1). The region is characterized by flat to rolling topography cut by numerous small rivers. Historically, the upland plant communities were dominated by longleaf pine forests (Pinus palustris), but these forests have largely changed to mixed pine-hardwood forests with strong representation of oaks (Quercus spp.) and loblolly (Pinus taeda) and slash (Pinus elliotii) pines (Ware et al. 1993). Riparian forests along low-order streams in upland areas are dominated by oaks, loblolly pine, and magnolias (Magnolia spp.). Riparian forests give way to extensive bottomland hardwood forests along major rivers, notably the Pearl and Pascagoula Rivers (see Plate 1), that are dominated by water oak (Quercus nigra), other oaks (Quercus sp.), black gum (Nyssa sylvatica), sweetgum (Liquidambar styraciflua), and spruce pine (Pinus glabra). Based on land cover classification of Landsat TM 5 imagery from 1999, nearly $70 \%$ of the study region is forested (Buler 2006). Non-forested lands consisting of urban areas, agricultural lands, clear-cut forests, bare ground, and coastal marshes comprise the remaining $30 \%$ of the land area. The dominant forest types are nearly equally amounts of pine forest and upland "hardwood" forests, given that our upland hardwood cover type includes an unknown amount of mixed pine-hardwood forests. Bottomland hardwood forests comprise only $7 \%$ of the land area.

We established 24 strip transects, $500 \mathrm{~m}$ long and 50 $\mathrm{m}$ wide, within hardwood forests of the study region. We stratified transects geographically among quadrants that divide the study region by longitude and latitude. The longitudinal divide provided two replicates of large bottomland hardwood forest ecosystems associated with the Pearl and Pascagoula Rivers. The latitudinal division provided two classes of transects located less than or more than $30 \mathrm{~km}$ from the coast of the Gulf of Mexico. We placed six transects within each quadrant, divided among two treatment levels of the amount of hardwood forest cover in the surrounding landscape; "high" forest cover sites were placed within contiguous bottomland forests and "low" forest cover sites were placed within narrow riparian forests along lower order tributaries that were bordered by pine forest. Transects were at least $1 \mathrm{~km}$ from the nearest neighboring transect (range $1-18 \mathrm{~km}$, mean of $5 \mathrm{~km}$ ) to ensure independence of observations of individual birds on a given day. During the course of fieldwork, we created four additional high forest cover transects as needed when access to original transects was temporarily blocked because of road closures or flooding. Thus, we created a total of 28 transects, but only 24 sites were sampled during each period. 


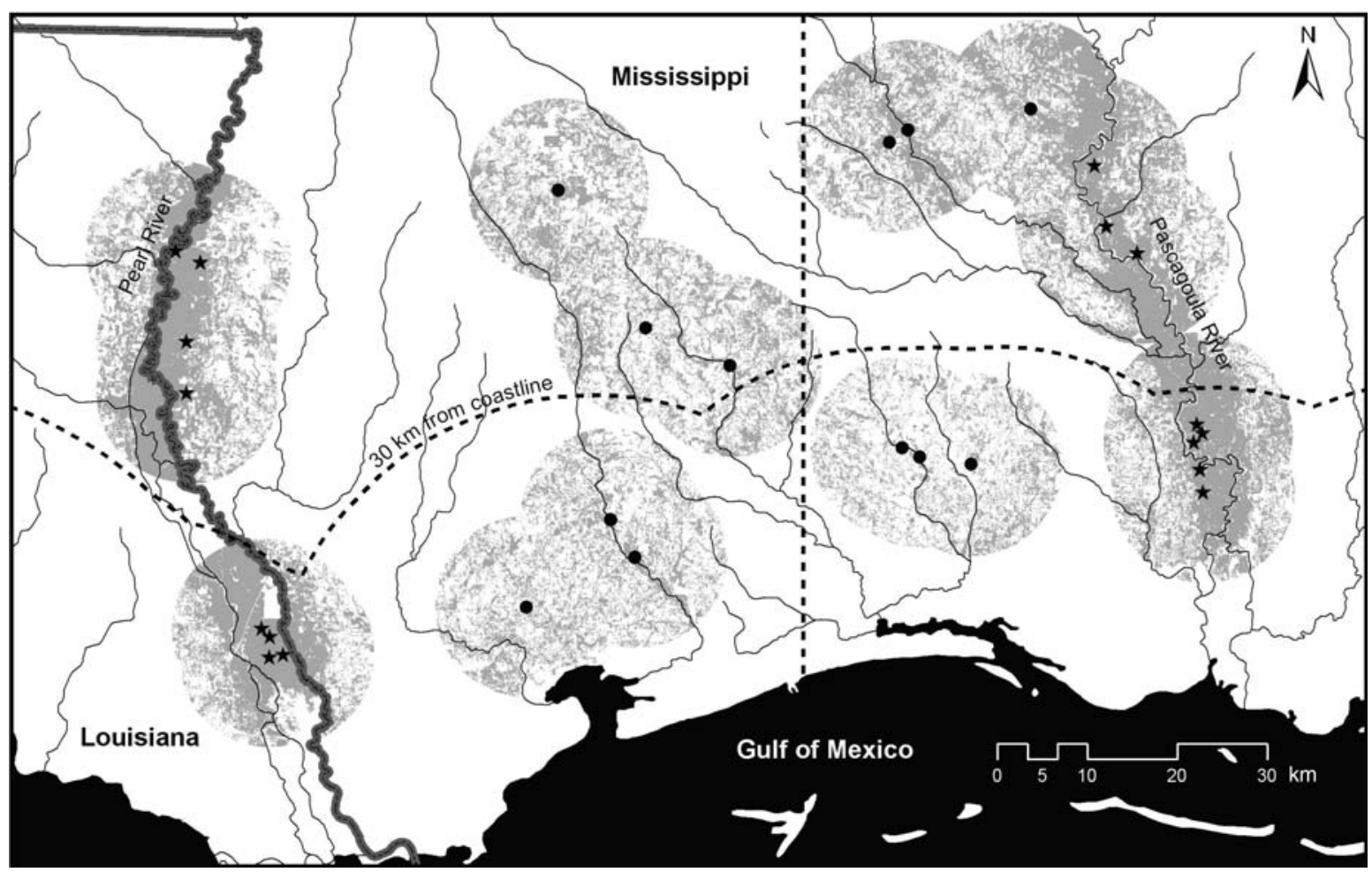

FIG. 1. Map of study region, southern Mississippi and Louisiana, USA. Center locations of strip transects are denoted by stars (high forest cover transects) and circles (low forest cover transects). Gray areas denote the extent of hardwood forest within $10 \mathrm{~km}$ of transects. Dashed lines delineate quadrant divisions.

\section{Bird surveys}

Observers conducted bird surveys at transects daily during the first four hours after sunrise for two autumn seasons (early September to the end of October 2002 and 2003) and two spring seasons (mid-March to early May 2003 and 2004). For each survey, one observer took 30 minutes to walk along the center of the transect and record the species, number and perpendicular distance class from the transect centerline $(0-5 \mathrm{~m}, 5-10 \mathrm{~m}$, or $10-$ $25 \mathrm{~m}$ ) of all individual land birds detected. Individual transects were surveyed every two to three days, weather permitting. We classified birds as Nearctic-Neotropical migrants (hereafter Neotropical migrants) following DeGraaf and Rappole (1995). Exceptions include American Robin (Turdus americanus), Blue-headed Vireo (Vireo solitarius), Eastern Phoebe (Sayornis phoebe), Golden-crowned Kinglet (Regulus satrapa), Hermit Thrush (Catharus guttatus), Orange-crowned Warbler (Vermivora celata), Ruby-crowned Kinglet (Regulus calendula), Yellow-bellied Sapsucker (Sphyrapicus varius), and Yellow-rumped Warbler (Dendroica coronata), which we did not consider as Neotropical migrants because substantial populations winter north of $25^{\circ} \mathrm{N}$ (American Ornithologists' Union 1998), and individuals of these species regularly overwinter in Mississippi (Turcotte and Watts 1999). We excluded observations of Common Grackles (Quiscalus quiscula) from data analyses because they occurred sporadically in large flocks during autumn.

We estimated detection probabilities of birds during strip-transect surveys to assure that all birds were detected within the strip transects before calculating bird densities. We pooled bird observations across years and species at each transect, and used the program Distance (Thomas et al. 2005) to fit a half-normal key function through the frequency of bird detections within the three distance categories for each transect to estimate the overall detection probability. Modeled detection functions exhibit pooling robustness to variation in detection probability among individual species (Buckland et al. 2001). We also calculated detection probabilities for individual species by pooling observations across transects of the same quadrat by forest cover treatment (i.e., eight groups of transects) for those species with at least 200 detections across years within a given migration season. This criterion represented a trade-off in sample size for accurate estimation of detection probabilities and the number of species that could be analyzed.

We only adjusted bird densities using detection probabilities for those transects where the $95 \%$ confidence interval of the detection probability was less than one. Bird densities are presented as the number of birds per five hectares. Seasonal mean bird density for each transect was calculated for each sampling period and then averaged across years. We estimated within-season 


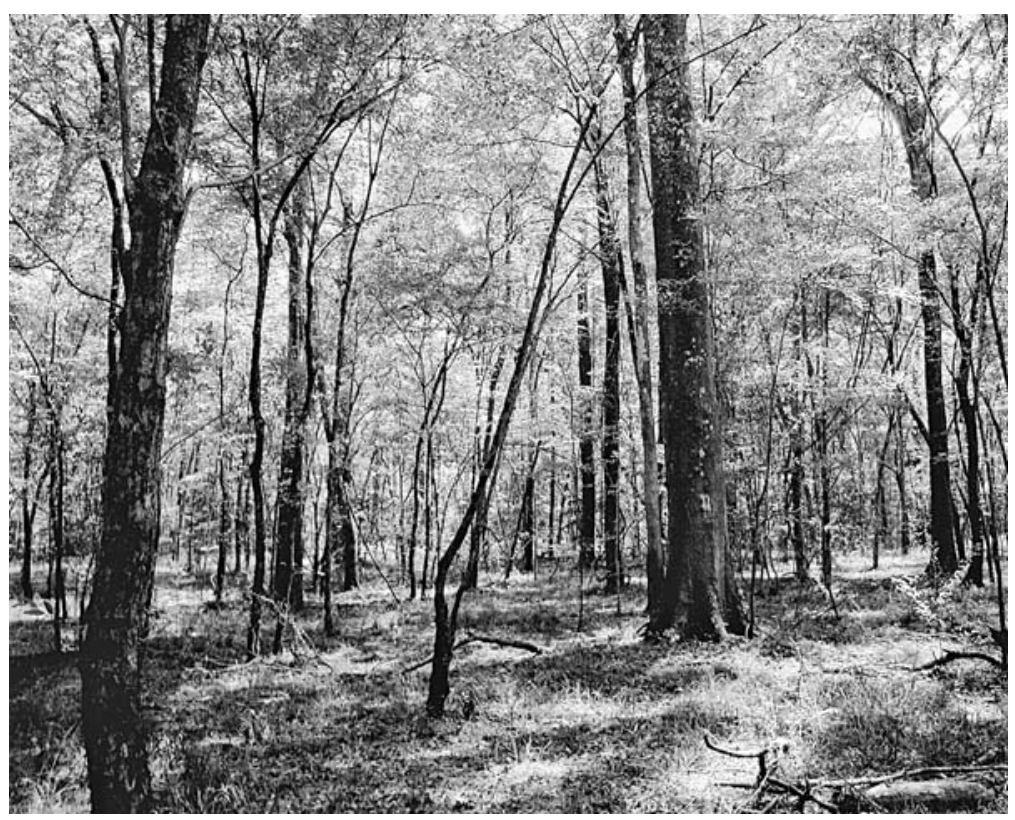

Plate 1. Photograph of bottomland hardwood forest habitat along the Pascagoula River in George County, Mississippi, USA. Photo credit: J. J. Buler.

coefficient of variation (CV) of bird densities for each transect by pooling samples across years and correcting for differences in sample sizes (Sokal and Rohlf 1995). Seasonal mean bird density and CV of bird density were each evaluated as dependent variables for the linear regression analyses.

\section{Regional and landscape scale variables}

Within our study region, extrinsic constraints on birds can possibly lead to habitat use patterns that are related to the proximity of habitats to the coast, as we discussed earlier for the case during spring. During autumn, some migrating birds that venture over water engage in reverse flights back toward land in coastal areas and may concentrate in habitats closest to the coast (Åkesson 1996, Diehl et al. 2003). Therefore, we calculated the distance of transect centers to the nearest major coastline using coastline data provided by the U.S. Geological Survey (Watermolen 2005). The distance from the nearest coastline to each transect ranged from $8.5 \mathrm{~km}$ to $56.5 \mathrm{~km}$ (mean $33.0 \mathrm{~km}$ ).

The proportion of hardwood forest habitat in the landscape was the only landscape-scale variable that we considered for the linear regression analyses because most other landscape structure metrics are typically correlated with landscape composition (Gustafson 1998, Tischendorf and Fahrig 2000). In fact, both empirical (McGarigal and McComb 1995, Trzcinski et al. 1999, Lichstein et al. 2002) and theoretical studies (Fahrig $1997,1998,2002)$ reveal that landscape composition is a better predictor of bird distributions within forests than measures of habitat fragmentation. We calculated the amount of hardwood forest surrounding transects using classified Landsat 5 Thematic Mapper imagery from 1999 within ArcGIS 9.0 (McCoy and Johnston 2000). The proportion of hardwood forest cover in the landscape within $5 \mathrm{~km}$ of transect centerlines ranged from 0.17 to 0.86 (mean 0.59; Buler 2006).

We determined the scale at which bird groups and individual bird species responded most strongly (i.e., characteristic landscape scale) to the amount of hardwood forest cover in the landscape by assessing the correlations between bird densities and the proportion of hardwood forest cover surrounding transects among a nested set of 20 landscapes within $500 \mathrm{~m}$ to $10 \mathrm{~km}$ radii from the center line of transects at intervals of $500 \mathrm{~m}$ using the statistical software FOCUS (Holland et al. 2004). At large radii, some landscapes surrounding individual transects overlapped, compromising their statistical independence. We determined that nine transects could be included in the computation of correlations while maintaining spatial independence at the largest landscape scale. Therefore, we performed 500 correlations at each of the 20 landscape scales, resampling nine spatially independent transects for each correlation, to generate means and standard errors of correlation coefficients. We used the amount of hardwood forest cover at the landscape scale with the maximum absolute mean correlation coefficient (i.e., best fit) for each species or species group in subsequent linear regression analyses to determine the relative importance of forest cover in explaining bird densities.

Habitat-patch scale variables

Arthropod abundance.-Once a week, during each season, observers sampled arthropods on the ground 
with visual counts (Strong 2000) and within understory vegetation by standard branch-clipping (Cooper and Whitmore 1990) at all of the transects during the first fours hours after sunrise. Three samples using both techniques were taken at locations stratified along the length of each transect. Visual counts were used to estimate the abundance of arthropods available to birds that forage on the ground. During visual counts, observers knelt over a $0.25-\mathrm{m}^{2}$ area on the ground and recorded all arthropods seen within and entering the area during a 3-min scan without disturbing the leaf litter. Arthropod abundance on the ground is presented as the number of arthropods observed per sample. All observers were trained in the identification of arthropods, and the limited taxonomic resolution (all arthropods identified to Class, insects further identified to Order) rendered the method both efficient and accurate (Strong 2000). Branch samples were taken to estimate the abundance of arthropods available to birds that forage in foliage. Within $2 \mathrm{~m}$ above the ground, observers collected a branch with $\sim 40$ leaves on it from a deciduous understory plant, primarily Carpinus caroliniana, Hamamelis virginiana, or Acer rubrum. Arthropod abundance in the understory is presented as the number of arthropods observed per gram of vegetation (wet mass).

Habitat structure.-We quantified habitat structure within each transect following James and Shugart (1970). We sampled vegetation at three 0.04-ha plots per transect and measured (1) basal area of trees $\geq 5 \mathrm{~cm}$ diameter at breast height, (2) percentage of canopy cover, (3) percentage of mid-story cover $(2-5 \mathrm{~m}$ in height), (4) understory plant stem density (number of plant stems $<5 \mathrm{~cm}$ in diameter and $\geq 50 \mathrm{~cm}$ in height within a $5.5 \mathrm{~m}$ radius of the plot center), (5) percentage of ground covered by leaf litter, and (6) mean canopy height. Using principal components analysis (PCA), we functionally combined the six habitat structure variables into component variables using an orthogonal rotation method that minimizes the number of variables that have high loadings on each factor to simplify interpretation. We arbitrarily used only the first two principal components for subsequent linear regression analyses to limit the number of independent variables. The first component accounted for $29 \%$ of total variation (eigenvalue $=1.74$ ) and described a gradient of increasing understory vegetation density and litter cover on the ground. The second component accounted for $23 \%$ of total variation (eigenvalue $=1.39$ ) and described a gradient of decreasing tree basal area and increasing mid-story cover.

Plant community composition.-We quantified plant community composition within each transect using the vegetation sampling data. We characterized the tree community using the basal area of tree species with trunks $\geq 5 \mathrm{~cm}$ diameter at breast height, and the understory plant community using the density of plant species with stems $<5 \mathrm{~cm}$ in diameter and $\geq 50 \mathrm{~cm}$ in height. As with habitat structure variables, we used PCA to combine the basal area of the 15 most abundant tree species and stem density of the 15 most abundant understory plant species among transects into two component variables for use in subsequent linear regression analyses. The first component accounted for $16 \%$ of total variation (eigenvalue $=4.83$ ) and described a change from a hydric-habitat plant community with relatively high density of swamp cyrilla (Cyrilla racemiflora) stems in the understory and a large tree basal area component of sweetbay magnolia (Magnolia virginiana), swamp cyrilla, and black gum to a more mesic-habitat plant community with greater densities of American holly (Ilex opaca), witch hazel (Hamamelis virginiana), and dewberries (Rubus spp.) in the understory, and more water oak, sweetgum, and ironwood (Carpinus caroliniana) contribution to tree basal area. The second component accounted for $16 \%$ of total variation (eigenvalue $=4.64$ ), and effectively separated transects located in river floodplain forests from transects located within narrow riparian forest along lower order tributaries. The second component also described a gradient of increasing amounts of fleshy-fruited trees (e.g., American holly and southern magnolia) and American beech (Fagus grandifolia), and, in the understory, an increase in the amount of Florida anise tree (Illicium floridanum), with decreasing amounts of switchcane (Arundinaria gigantea) and sugarberry (Celtis laevigata).

\section{Data analysis}

We used multi-model inference within an information-theoretic approach to determine the relative importance and effect size of eight environmental variables in explaining seasonal mean and $\mathrm{CV}$ of bird densities at transects using simple linear regression models (Burnham and Anderson 2002). We analyzed spring and autumn data separately. Additionally, we analyzed Neotropical migrant species collectively as a group, split into two groups by general diet during autumn (insectivores and frugivores), and individually for commonly observed species. We separated frugivorous and insectivorous migrants during autumn because nearly half of all migrants detected during autumn were of species that are seasonally frugivorous (Parrish 1997), which can strongly affect their foraging behavior and habitat use (reviewed by Parrish 2000). We considered all thrushes, Gray Catbird, and Red-eyed Vireo (scientific names of all migrant species in Appendix A) as frugivorous during autumn (Blake and Hoppes 1986, Davidar and Morton 1986). Individually, we analyzed 13 species with at least 50 detections during all spring surveys and six species for which we corrected densities for detection probability during autumn.

The eight independent (or explanatory) variables included (1) one variable at the regional scale, the distance to the nearest major coastline (DIST); (2) one variable at the landscape scale, the arcsine-transformed proportion of hardwood forest cover within the landscape at the characteristic scale for the bird group/species 
TABLE 1. Correlation matrix of explanatory variables used in modeling bird densities at transects during spring $(n=27)$ and autumn $(n=26)$.

\begin{tabular}{|c|c|c|c|c|c|c|c|}
\hline $\begin{array}{l}\text { Variable, } \\
\text { by season }\end{array}$ & DIST & ARTU & ARTG & $\mathrm{FCOV} \dagger$ & HSC1 & HSC2 & PCC1 \\
\hline \multicolumn{8}{|l|}{ Autumn } \\
\hline ARTU & 0.24 & & & & & & \\
\hline ARTG & 0.06 & -0.05 & & & & & \\
\hline $\mathrm{FCOV} \dagger$ & 0.15 & $0.70^{* * *}$ & -0.02 & & & & \\
\hline $\mathrm{HSCl}$ & -0.37 & $-0.68^{* *}$ & 0.06 & $-0.68^{* *}$ & & & \\
\hline HSC2 & -0.17 & 0.05 & -0.17 & -0.08 & -0.01 & & \\
\hline $\mathrm{PCC} 1$ & -0.29 & $0.43^{*}$ & 0.05 & $0.45^{*}$ & -0.24 & -0.07 & \\
\hline PCC2 & -0.30 & $-0.65^{* *}$ & -0.10 & $-0.71^{* *}$ & $0.70^{* *}$ & -0.09 & 0.02 \\
\hline \multicolumn{8}{|l|}{ Spring } \\
\hline ARTU & 0.19 & & & & & & \\
\hline ARTG & -0.21 & $-0.50^{* *}$ & & & & & \\
\hline $\mathrm{FCOV} \uparrow$ & 0.18 & $0.41^{*}$ & -0.37 & & & & \\
\hline $\mathrm{HSCl}$ & -0.37 & $-0.59^{* *}$ & 0.24 & $-0.68^{* *}$ & & & \\
\hline HSC2 & -0.07 & 0.22 & -0.06 & -0.07 & 0.00 & & \\
\hline $\mathrm{PCCl}$ & -0.27 & 0.04 & 0.09 & $0.46^{*}$ & -0.25 & -0.08 & \\
\hline $\mathrm{PCC} 2$ & -0.30 & $-0.47^{*}$ & 0.37 & $-0.72^{* *}$ & $0.71^{* *}$ & -0.10 & 0.01 \\
\hline
\end{tabular}

Notes: Values shown are Pearson correlation coefficients. Asterisks indicate levels of significance of the correlation (two-tailed): ${ }^{*} P<0.05 ; * * P<0.01$. Variables are: DIST, distance to nearest major coastline (regional scale); FCOV, the arcsine-transformed proportion of hardwood forest cover within the landscape at the scale for the bird group/species considered (landscape scale); patch-scale variables ARTG and ARTU, mean arthropod abundance on the ground and within understory vegetation, respectively; HSC1 and $\mathrm{HSC} 2$, component variables describing habitat structure; $\mathrm{PCC} 1$ and $\mathrm{PCC}$, component variables describing plant community structure.

$\dagger$ For a $5 \mathrm{~km}$ radius.

considered (FCOV); and (3) six variables at the patch scale: mean arthropod abundance on the ground (ARTG) and within understory vegetation (ARTU), the two component variables describing habitat structure (HSC1 and HSC2), and the two component variables describing plant community structure (PCC1 and PCC2). We tested all possible variable pairs to assess the degree of correlation among variables (Table 1). Four variables were not strongly correlated (|Pearson $r \mid<$ 0.50 ) with any other variable (i.e., ARTG, DIST, HSC2, PCC1). The remaining four variables were correlated with one or more variables, with the maximum correlation of -0.72 between FCOV (within $5 \mathrm{~km}$ radius) and PCC2 during spring. We interpret the results of the modeling analyses considering these correlations.

Because a balance in the number of models that contain each variable is desirable when determining relative variable importance, we tested all possible subsets of models (255 models). We used Akaike's Information Criterion adjusted for small sample sizes $\left(\mathrm{AIC}_{\mathrm{c}}\right)$ to rank models based on their ability to explain the data, and used Akaike weights (w) to estimate the relative likelihood of each model, given the data (Akaike 1973, Hurvich and Tsai 1989, Burnham and Anderson 2002). We summed Akaike weights across all the models containing the variable of interest to estimate the relative importance of explanatory variables. To determine the direction and magnitude of effect sizes for explanatory variables, we calculated the mean standardized regression coefficient $\left(\hat{\bar{\beta}}_{\mathrm{S}}\right)$ across all of the models containing the variable of interest, and estimated precision using an unconditional variance estimator that incorporates model selection uncertainty (Burnham and Anderson 2002:162). Using this variance estimate, we calculated $95 \%, 90 \%$, and $85 \%$ confidence intervals (CI) of each $\hat{\bar{\beta}}_{\mathrm{S}}$ and scored the magnitude of effect as "no effect" where the $85 \%$ CI spans zero, "weak effect" where the $85 \%$ CI does not span zero, "moderate effect" where the $90 \% \mathrm{CI}$ does not span zero, and "strong effect" where the 95\% CI does not span zero (sensu Skagen et al. 2005). We calculated the adjusted coefficient of determination $\left(r^{2}\right)$ of the linear model that included only those explanatory variables exhibiting effects ("effects" model) to determine the amount of variation explained.

\section{RESULTS}

Observers detected 25732 individual birds during a total of 1914 transect surveys, and visited each transect an average of 20 (range 5-29) times during any one sampling season. The $95 \%$ confidence intervals of detection probability of migrants at 8 of 26 (31\%) transects were below 1.0 during autumn. During spring, however, the detection probability of migrants was below 1.0 at only 1 of $27(4 \%)$ transects. Therefore, we adjusted bird density estimates for detection probability only during autumn. On average, 77 land bird species were observed per season, with mean land bird density at transects with a mean of $27 \mathrm{birds} / 5$ ha (ranging from 11 to $48 \mathrm{birds} / 5 \mathrm{ha}$ ) during spring, and $33 \mathrm{birds} / 5$ ha (range 13-62) during autumn across years. Neotropical migrants comprised a greater percentage of all land birds detected during spring (46\%) than during autumn (34\%; paired $t=3.4$, df $=24, P<0.01$ ). Mean 


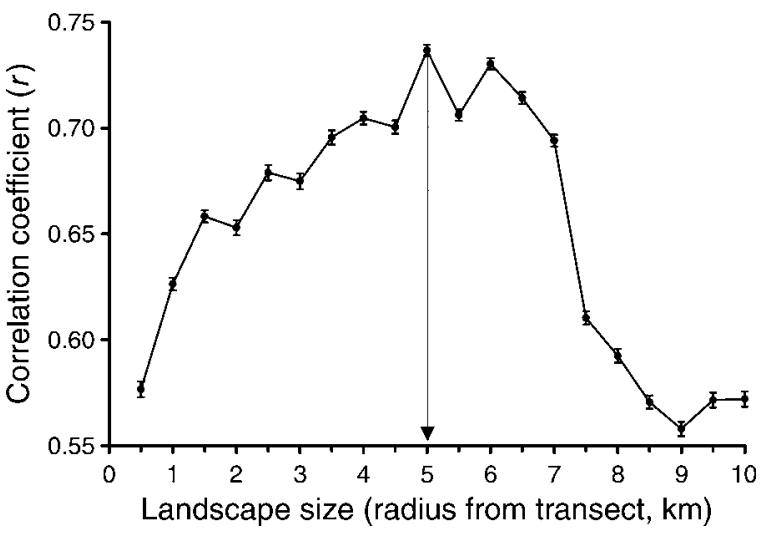

FIG. 2. Partial correlation (mean \pm SE) between spring mean Neotropical migratory land bird density and the proportion of hardwood forest cover surrounding transects, by landscape size, where variation of other variables that influenced bird density and were correlated to forest cover (i.e., ARTU and PCC1; see Methods: Data analysis) was held constant. Means at each landscape size are derived from 500 correlations, with each correlation using data from a randomly chosen set of nine spatially independent transects among 27 possible transects. The vertical arrow indicates the characteristic landscape scale at which birds responded to hardwood forest cover (i.e., maximum correlation).

Neotropical migrant density at transects was 12.5 birds $/ 5$ ha (range 2.1-26.2 birds) during spring, and 12.3 birds/5 ha (range 3.5-30.6 birds) during autumn across years. Although the mean density of Neotropical migrants did not differ at transects between seasons (paired $t=-0.2, \mathrm{df}=24, P=0.87$ ), density was more variable at transects during autumn (paired $t=-3.1$, df $=24, P<0.01)$. The coefficient of variation of Neotropical migrant density at transects ranged from $44 \%$ to $143 \%$ (mean $=81 \%$ ) during spring, and from $63 \%$ to $144 \%$ (mean $=96 \%$ ) during autumn across years. The correlation between seasonal mean density and $\mathrm{CV}$ of density was significant only during spring $(r=-0.72, n=$ 27, $P<0.01)$.

Observers conducted a total of 583 arthropod surveys and visited each transect an average of six times (range 4-9) during any one sampling season. Arthropod abundance in the understory was about four times greater $(t=2.9, \mathrm{df}=24, P<0.01)$ during spring (mean 0.40 arthropods/g vegetation; range $0.06-2.48$ ) than during autumn (mean 0.09; range 0.04-0.19). Arthropod abundance on the ground during spring (mean 3.6 arthropods $/ 0.25-\mathrm{m}^{2}$ area per 3-min scan; range $\left.1.4-5.5\right)$ was similar $(t=0.5, \mathrm{df}=24, P=0.64)$ to that during autumn (mean 3.5 arthropods $/ 0.25-\mathrm{m}^{2}$ area per 3 -min scan; range 2.2-4.8). The most common arthropods were hemipterans, arachnids, and dipterans during spring, and arachnids, dipterans, and lepidopteran larvae during autumn.

Correlations between bird density and hardwood forest cover generally varied moderately among landscapes of different sizes and exhibited unimodal distributions (see Fig. 2). The mean characteristic scale of response to forest cover in the landscape across individual Neotropical migrant species whose densities were related to the amount of forest cover was a $5.3 \mathrm{~km}$ radius during spring $(n=4)$ and a $4.9 \mathrm{~km}$ radius during autumn ( $n=4$; Table 2$)$, based on post hoc analyses for which we determined the characteristic scale of response to forest cover in the landscape while statistically holding constant those explanatory variables correlated with forest cover, following Sokal and Rohlf (1995). Across seasons, the characteristic landscape scale of individual species, on average, was a $5.1 \mathrm{~km}$ radius and ranged from $1.0 \mathrm{~km}$ to $8.5 \mathrm{~km}(n=7)$.

\section{Linear regression modeling analyses}

Spring.-For all Neotropical migrants combined, four explanatory variables exhibited strong effects and explained $86 \%$ of the variation of mean bird density (Fig. 3A). The most important explanatory variable of mean bird density was the proportion of hardwood forest cover in the landscape. Overall, migrant density increased with increasing forest cover in the landscape, increasing arthropod abundance in the understory, closer proximity to the coast, and a change from hydric to mesic plant communities (see Appendix B for partial regression plots of each independent variable in the "effects" model). Three explanatory variables exhibited moderate or strong effects and explained $50 \%$ of the variation of $\mathrm{CV}$ of bird density (Fig. 3B). The most important explanatory variable of mean bird density was arthropod abundance in the understory. Overall, migrant density was less variable with increasing arthropod abundance in the understory, increasing forest cover in the landscape, and a change from hydric to mesic plant communities.

For 11 of 13 species with sufficient data, one to three explanatory variables explained from $4 \%$ to $63 \%$ (mean

TABLE 2. Characteristic scale of response to hardwood forest cover for those bird species and other response variables that were affected by the amount of forest cover during at least one season.

\begin{tabular}{lcc}
\hline \hline \multirow{2}{*}{ Response variable } & \multicolumn{2}{c}{ Scale of response (radius, in km) } \\
\cline { 2 - 3 } & Spring & Autumn \\
\hline Acadian Flycatcher & $\dagger$ & 5.5 \\
American Redstart & $\dagger$ & 1.0 \\
Blue-gray Gnatcatcher & 6.5 & $\mathrm{n} / \mathrm{a}$ \\
Hooded Warbler & $\dagger$ & 6.5 \\
Northern Parula & 1.0 & $\mathrm{n} / \mathrm{a}$ \\
Prothonotary Warbler & 8.5 & $\mathrm{n} / \mathrm{a}$ \\
White-eyed Vireo & $5.0(1.5)$ & $6.5(5.5)$ \\
All Neotropical migrants & $5.0(1.5)$ & $\dagger$ \\
\hline
\end{tabular}

Notes: The scale of response was determined from post hoc analysis in which other important explanatory variables correlated with forest cover were held constant. Values in parentheses show the a priori scale of response used for the regression modeling analysis when different from the post hoc scale; $\mathrm{n} / \mathrm{a}$ indicates not assessed.

$\dagger$ The amount of forest cover had no discernible effect in explaining variation of seasonal mean density. 


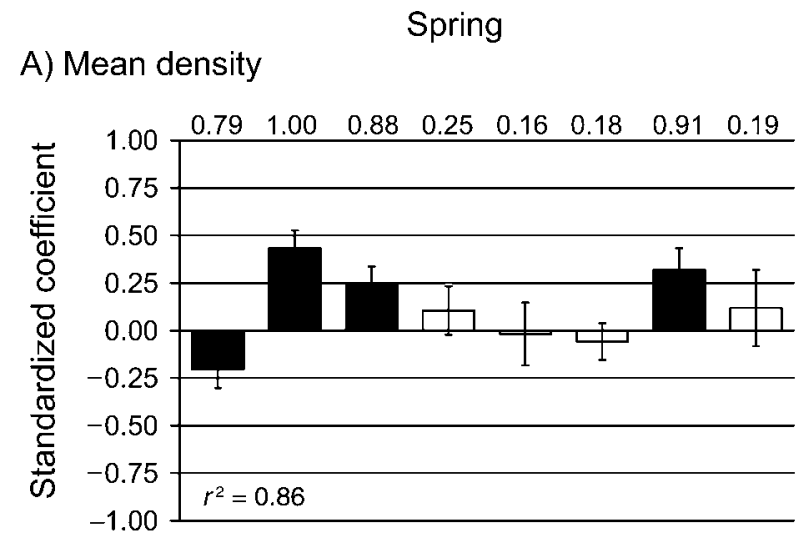

Autumn

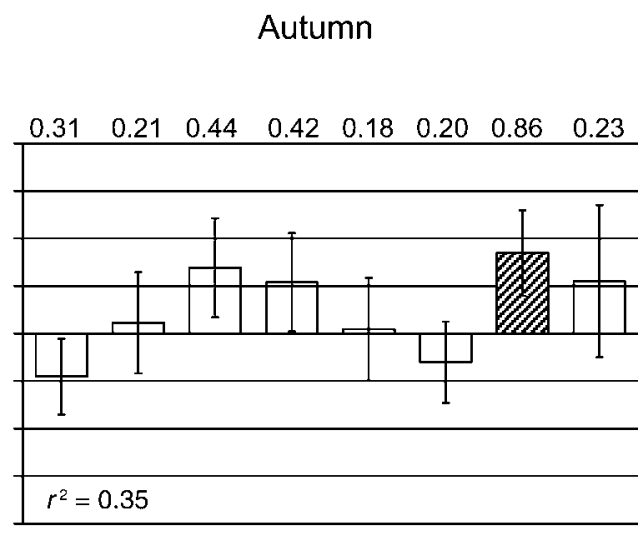

\section{B) Coefficient of variation of density}
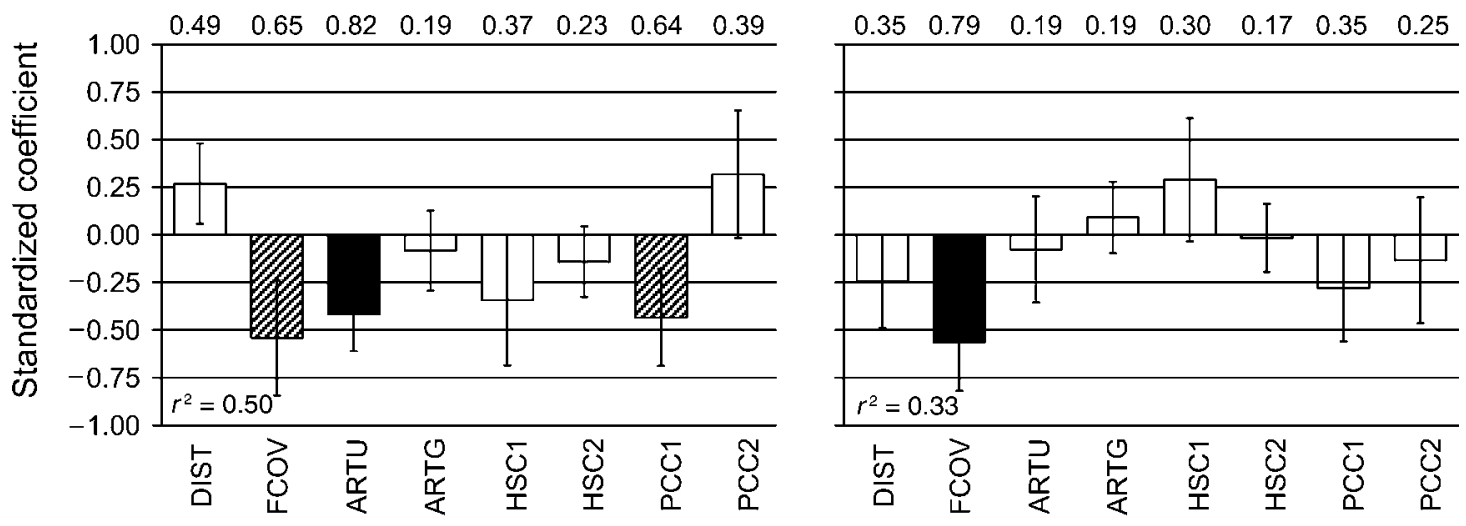

\section{Explanatory variables}

FIG. 3. Relative effect size of explanatory variables (standardized model-averaged coefficient, mean \pm SE) on (A) mean density and (B) coefficient of variation of density for Neotropical migrant birds, by season. Relative variable importance is denoted above bars. Bar shading reflects the effect score: open bars, no effect ( $85 \% \mathrm{CI}$ spans zero); hatched bars, moderate effect (90\% CI does not span zero); solid bars, strong effect (95\% CI does not span zero). Explanatory variables are: DIST, distance to nearest major coastline (regional scale); FCOV, the arcsine-transformed proportion of hardwood forest cover within the landscape at the scale for the bird group/species considered (landscape scale); and patch-scale variables ARTU and ARTG, mean arthropod abundance within understory vegetation and on the ground, respectively; HSC1 and HSC2, component variables describing habitat structure; PCC1 and PCC2, component variables describing plant community structure. Adjusted $r^{2}$ of the linear model including only explanatory variables exhibiting effects is presented.

$=34 \%$ ) of the variation in mean density (see Appendix C). For the remaining two species, none of the variables had any explanatory effect. All explanatory variables except ARTG and HSC2 affected at least one species (Table 3). PCC1 was the most important explanatory variable of mean density for the majority of species (55\%). Most species affected by PCC1 increased with a change from hydric to mesic plant communities. FCOV was the most important explanatory variable of mean density for three species (27\%), such that densities increased with increasing forest cover in the landscape. DIST was the only other variable to exhibit strong effects on mean densities, where the densities of four species were greater, and, for two of these species, were less variable near the coast.

For seven of 12 species with sufficient data, one to three explanatory variables explained from $25 \%$ to $70 \%$ (mean $=46 \%)$ of the variation of $\mathrm{CV}$ of bird density (see Appendix D). FCOV was the most important explanatory variable of $\mathrm{CV}$ for the majority of species (57\%), such that bird densities were less variable with increasing forest cover in the landscape. PCC1 was the most important explanatory variable of $\mathrm{CV}$ for the remainder of species $(43 \%)$, such that bird densities were less variable with a change from hydric to mesic plant communities. No other variables had strong effects on $\mathrm{CV}$ of bird densities.

Autumn.-For all Neotropical migrants combined, PCC1 exhibited a moderate effect and explained 35\% of the variation of mean bird density, such that migrant density increased with a change from hydric to mesic plant communities. For the subset of insectivorous migrants, FCOV was the most important explanatory variable of mean bird density (Fig. 4A). Overall, 
TABLE 3. Number of bird species whose densities were affected by explanatory variables, organized by season and density parameter.

\begin{tabular}{lccccc}
\hline \hline & \multicolumn{2}{c}{ Spring } & & \multicolumn{2}{c}{ Autumn } \\
\cline { 2 - 3 } \cline { 5 - 6 } $\begin{array}{l}\text { Explanatory } \\
\text { variable }\end{array}$ & $\begin{array}{c}\text { Mean density } \\
\text { (13 species) }\end{array}$ & $\begin{array}{c}\text { CV of density } \\
\text { (12 species) }\end{array}$ & & $\begin{array}{c}\text { Mean density } \\
\text { (6 species) }\end{array}$ & $\begin{array}{c}\text { CV of density } \\
\text { (6 species) }\end{array}$ \\
\hline DIST & $4(0)$ & $2(0)$ & & $2(0)$ & $3(1)$ \\
FCOV & $4(3)$ & $4(4)$ & & $4(4)$ & $3(3)$ \\
ARTU & 0 & $1(0)$ & & $1(0)$ & $2(0)$ \\
ARTG & 0 & $1(0)$ & & $1(0)$ & 0 \\
HSC1 & $2(1)$ & 0 & 0 & 0 \\
HSC2 & 0 & $3(3)$ & & $2(1)$ & 0 \\
PCC1 & $7(6)$ & $1(0)$ & & $2(1)$ & $4(2)$ \\
PCC2 & $1(1)$ & $10)$ &
\end{tabular}

Notes: The number of species for which that explanatory variable is the most important is given in parentheses. See Table 1 and Methods: Data analysis for descriptions of explanatory variables

insectivore density increased with increasing forest cover, closer proximity to the coast, and increasing arthropod abundances on the ground and in the understory (see Appendix E for partial regression plots of each independent variable in the "effects" model). For the subset of frugivorous migrants, PCC2 was the most important explanatory variable of mean bird density, such that the density increased with increasing proportion of fleshy-fruited trees (see Appendix F). For all Neotropical migrants combined, FCOV exhibited a strong effect and explained 33\% of the variation of CV of bird density, such that bird density was less variable with increasing forest cover in the landscape. Similarly, FCOV was the most important explanatory variable of $\mathrm{CV}$ of bird density for the subset of insectivorous migrants (Fig. 4B). The subset of frugivorous migrants, however, was less variable with increasing proportion of fleshy-fruited trees and increasing distance from the coast.

For six species with sufficient data, one to three variables explained from $28 \%$ to $66 \%$ (mean $54 \%$ ) of the variation in mean bird density. All explanatory variables except HSC2 affected the density of at least one species. FCOV was the most important explanatory variable for the majority of species (67\%), such that densities increased with increasing forest cover in the landscape. PCC1 was the most important explanatory variable for one species (Gray Catbird), which increased in density with a change from mesic to hydric plant communities. PCC2 was the most important explanatory variable for Wood Thrush, which increased in density with an increasing proportion of fleshy-fruited trees.

For the same six species, one to three variables explained from $33 \%$ to $61 \%$ (mean $48 \%$ ) of the variation of CV of bird density. FCOV was the most important explanatory variable for half of the species, such that bird densities were less variable with increasing forest cover in the landscape. PCC2 was the most important explanatory variable for two species (33\%), affecting four species overall. The densities of Gray Catbird and Wood Thrush were less variable with an increasing proportion of fleshy-fruited trees, whereas Hooded
Warbler and White-eyed Vireo had the opposite relationship. The densities of the three smallest species at sites closer to the coast were either relatively greater (White-eyed Vireo), less variable (Hooded Warbler), or both (American Redstart). The mean density for the remaining species did not change with proximity to the coast except for Wood Thrush, the largest species tested, which had less variable density farther inland. Wood Thrushes comprised $67 \%$ of all frugivorous Neotropical migrants detected and largely explain our observed pattern of frugivorous Neotropical migrant distributions with proximity to the coast.

\section{Discussion}

Regional scale

Our analysis of en route habitat use by Neotropical migratory birds along the Mississippi Gulf Coast revealed that many migrants stop over in greater densities with closer proximity to the coastline. These results are consistent with observations from weather surveillance radar studies (Gauthreaux 1971, Gauthreaux and Belser 1999, Buler 2006) and anecdotal observations in the literature over the last 60 years (e.g., Lowery 1945, Williams 1950). Ours is the first study, of which we are aware, to quantify this phenomenon at a large scale through on-the-ground surveys. Although proximity to the coast was less important overall than other landscape- and patch-scale factors in explaining seasonal mean migrant distributions, it is probably of critical importance to some migrants some of the time due to energy or weather-imposed constraints that arise when negotiating large ecological barriers to migration such as the Gulf of Mexico, both in spring after having crossed the Gulf (Gauthreaux 1971, Moore et al. 1990, Kuenzi and Moore 1991, Spengler et al. 1995) and in autumn when preparing to cross the Gulf (Akesson 1996, 1999, Diehl et al. 2003).

\section{Landscape scale}

The amount of hardwood forest cover at a landscape scale (i.e., landscape composition) was most important 
A) Mean density

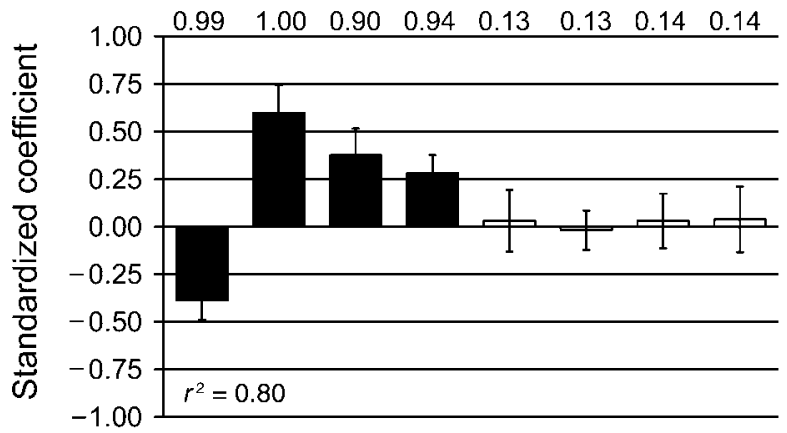

B) Coefficient of variation of density

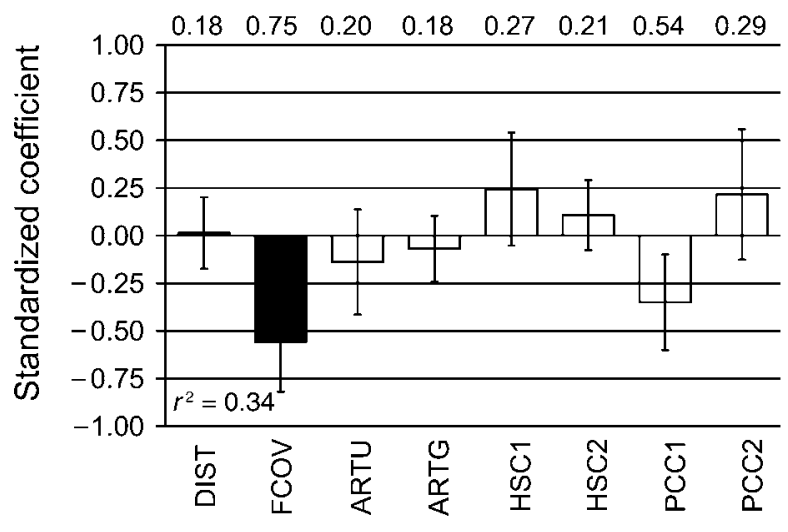

Explanatory variables

\section{Frugivores}
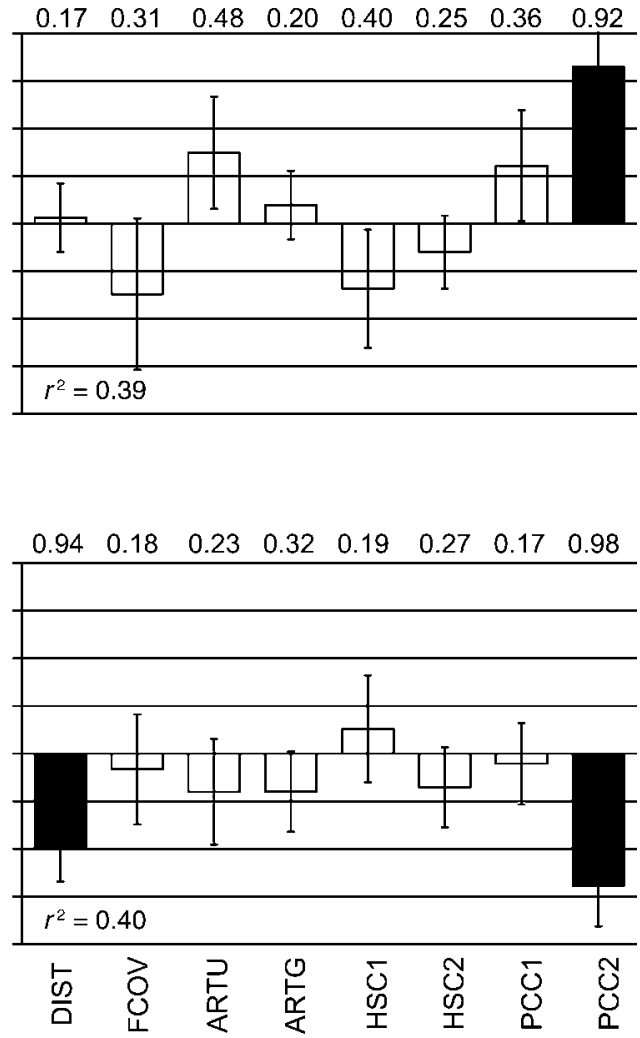

FIG. 4. Relative effect size of explanatory variables (standardized model-averaged coefficient \pm SE) on (A) mean density and (B) coefficient of variation of density for Neotropical migrant birds during autumn, by diet. Relative variable importance is denoted above bars. Bar shading reflects effect score: open bars, no effect (85\% CI spans zero); solid bars, strong effect (95\% CI does not span zero). Explanatory variables are defined in Fig. 3; for details, see Methods: Data analysis. Adjusted $r^{2}$ of the linear model including only explanatory variables exhibiting effects is presented.

in explaining distributions of insectivorous migrants during both spring and autumn. Conversely, the amount of forest cover did not explain the distribution of frugivores, at least during autumn. On the breeding grounds, landscape-scale factors are often better predictors of bird distributions than patch-scale factors (Saab 1999, Lee et al. 2002; but see Lichstein et al. 2002). For migrants en route, we argue that hardwood forest cover is likely to be an indicator of habitat quality that birds use as a cue when selecting a landing site at the end of a migratory flight. It is the choice of a landing site that largely determines how migrants are distributed (Jenni and Schaub 2003), because migrants remain in relatively close proximity to their landing site.

Two lines of evidence lead us to suggest that the amount of hardwood forest cover at a landscape scale is an indicator of habitat quality for insectivores. First, the densities of all species influenced by forest cover were greater with increasing forest cover. Although density by itself is not necessarily an indicator of habitat quality (van Horne 1983), bird densities at sites with high forest cover for all affected species were also less variable, and stable densities are thought to indicate higher habitat quality (Brown 1969). Second, forest cover was positively correlated with arthropod abundance in the understory. Thus, high forest cover sites are probably of better quality than low forest cover sites for insectivorous migrants.

Hardwood forest cover in the landscape may to serve as a cue that allows insectivores to correctly and quickly assess habitat quality during landfall at the end of a migratory flight. We raise this possibility because the mean scale $(5 \mathrm{~km})$ at which migrants responded to forest cover is an order of magnitude greater than the maximum distance $(<500 \mathrm{~m})$ that most migrant species are known to range "on the ground" after landfall during stopover, based on radiotelemetry (Aborn and Moore 1997, Cochran and Wikelski 2003, Chernetsov et al. 2004, Buler 2006). Moreover, there is evidence that migrating birds adjust their flight path to the landscape 
below and select appropriate habitats based on visual and acoustic cues during landfall at night (Heeremans 1990, Martin 1990, Jenni 1996, Jenni-Eiermann and Jenni 1999). In fact, Bowlin et al. (2005) observed an increase in heart rate and wing beat frequency in migrating thrushes about 15 minutes before landing, which may indicate a change in the flight style of birds as they search for suitable landing sites. A thrush flying for 15 minutes at a mean flight speed of $49 \mathrm{~km} / \mathrm{h}$ (from Bowlin et al. 2005) could easily cover the $5 \mathrm{~km}$ radius range that represents the mean scale at which migrants responded to forest cover.

In our study, only three sites had forest cover in the 5 $\mathrm{km}$ radius landscape below 30\%, indicating that fragmentation effects were probably negligible. Previous work by others suggests that only when the amount of habitat in the landscape drops below a critical threshold (e.g., 10-30\% for birds and mammals; Andrén 1994) does habitat fragmentation alter habitat selection such that migrants use smaller or more isolated patches in greater density (e.g., Skagen et al. 1998, Somershoe and Chandler 2004). We encourage future investigations of the importance of additional landscape metrics for habitat selection and use by birds en route, especially in more depauperate landscapes.

\section{Habitat-patch scale}

After landfall, intrinsic habitat factors, namely food abundance, become important in determining fine-scale settlement patterns of migrants because migrants can sample habitats directly (Petit 2000, Chernetsov 2006). At the patch scale, densities of insectivorous migrants were positively related to arthropod abundance and to more mesic plant communities, whereas densities of frugivorous migrants during autumn were positively related to the relative amount of fleshy-fruited trees. We found that habitat structure variables were generally the poorest predictors of bird densities among the variables that we examined. Others have also found no or weak relationships between habitat structure and bird abundance among habitats (Parnell 1969, McCann et al. 1993) and within habitats during migration (Martin 1980, Skagen et al. 1998, Somershoe and Chandler 2004).

The first principal component of plant community composition (PCC1) described a change from hydric to more mesic plant communities. All individual bird species affected by PCC1 were primarily insectivorous and had greater densities within mesic plant communities across seasons, except for Prothonotary Warbler (which preferentially breeds within hydric plant communities; Petit 1999) and Summer Tanager during spring. Mesic-forested wetlands that are periodically flooded are known to have greater primary productivity than hydric-forested wetlands flooded nearly year-round (Mitsch et al. 1991). Greater primary productivity may create a trophic cascade of increased arthropod abundance and, subsequently, greater bird density within mesic forests (Oksanen et al. 1981, Letourneau and Dyer 1998, Forkner and Hunter 2000). Consistent with this, we found that arthropod abundance in the understory in autumn was greater in mesic plant communities than in hydric plant communities. In particular, witch hazel and ironwood, which were more abundant in mesic plant communities, are known to harbor high abundances of arthropods (Parnell 1969, Futuyma and Gould 1979).

\section{Conclusions}

This is the first study of which we are aware that concurrently compares the influence of factors operating at different spatial scales in explaining habitat use patterns of en route land bird migrants at multiple sites over a large $\left(1 \times 10^{6} \mathrm{ha}\right)$ area. The effects of energy- and weather-imposed constraints on habitat use by migrants when negotiating the Gulf of Mexico were evident as a regional pattern of increased bird density with proximity to the coast. Although these constraints played a moderate role in explaining migrant distributions, our results are consistent with the view that food availability is the ultimate and overriding factor shaping the distributions of birds during stopover (reviewed in Hutto 1985 and Petit 2000). Yet, our findings challenge the commonly held idea that the process of habitat selection occurs primarily after landfall (Moore and Aborn 2000). Instead, we found that migrant densities were associated with landscape features that, in combination with evidence from other studies, are consistent with recent ideas that migrants make initial habitat selection during landfall (sensu Chernetsov 2006) and that the choice of landing site largely explains habitat use patterns (Jenni and Schaub 2003). Insectivore density was associated with the amount of hardwood forest cover in the landscape, which was correlated with arthropod abundance, whereas frugivore density may be associated with other landscape features that we did not explicitly consider. We encourage investigation of other factors that may better explain the distributions of en route frugivorous migrant land birds. Furthermore, although they are probably less important than food availability in shaping en route migrant distributions (Petit 2000), consideration of factors that are embedded in trade-offs with food availability for energetic gain, such as the abundance of competitors (Rappole and Warner 1976, Moore and Wang 1991) and predation pressure (Lindström 1990, Cimprich et al. 2005), should be pursued using a multi-scale approach.

\section{ACKNOWLEDGMENTS}

We acknowledge those biologists who gathered field data: V. Adams, J. Breeden, A. Finfera, N. Hanke, D. Hof, K. Judson, J. Mollenhauer, B. Ogle, T. Rodriguez, K. Sash, R. Stranges, M. Thibodeau, M. Woodrey, B. Wright, K. Wright, and B. Zitske. George Roedl of the Department of Geography at The University of Southern Mississippi performed the land cover classification. We thank landowners for allowing access to their properties: Joe Feil, the Hancock and Harrison Counties School Districts, the Louisiana Department of Wildlife and Fisheries, the Mississippi Department of Marine Resources, the 
Mississippi Department of Wildlife, Fisheries and Parks, the U.S. Forest Service, the U.S. Fish and Wildlife Service, and Weyerhaeuser. This research was funded by a grant from the Coastal Impact Assistance Program and administered by the Mississippi Department of Environmental Quality. We also thank the two anonymous reviewers who provided helpful comments for the manuscript.

\section{Literature Cited}

Aborn, D. A., and F. R. Moore. 1997. Pattern of movement by summer tanagers (Piranga rubra) during migratory stopover: a telemetry study. Behaviour 134:1-24.

Akaike, H. 1973. Information theory as an extension of the maximum liklihood principle. Pages 267-281 in B. N. Petrov and F. Csaki, editors. Second International Symposium on Information Theory, Akademiai Kiado, Budapest, Hungary.

Åkesson, S. 1996. Bimodal orienation and the occurence of temporary reverse bird migration during autumn in south Scandinavia. Behavioural Ecology and Sociobiology 38:293302.

Åkesson, S. 1999. Do passerines captured at an inland ringing site perform reverse migration in autumn? Ardea 87:129-138.

Alerstam, T. 2003. Bird migration speed. Pages 253-267 in P. Berthold, E. Gwinner, and E. Sonnenschein, editors. Avian migration. Springer-Verlag, Berlin, Germany.

American Ornithologists' Union. 1998. Checklist of North America Birds. Seventh edition. American Ornithologists' Union, Washington, D.C., USA.

Andrén, H. 1994. Effects of habitat fragmentation on birds and mammals in landscapes with different proportions of suitable habitat: a review. Oikos 71:355-366.

Bairlein, F. 1983. Habitat selection and associations of species in European passerine birds during southward, post-breeding migrations. Ornis Scandinavica 14:239-245.

Berthold, P. 1975. Migration: control and metabolic physiology. Pages 77-128 in D. S. Farner and J. R. King, editors. Avian biology. Academic Press, New York, New York, USA.

Blake, J. G., and W. G. Hoppes. 1986. Influence of resource abundance on use of tree-fall gaps by birds in an isolated woodlot. Auk 103:328-340.

Blem, C. R. 1980. The energetics of migration. Pages 175-224 in S. A. J. Gauthreaux, editor. Animal migration, orientation, and navigation. Academic Press, New York, New York, USA.

Bowlin, M. S., W. W. Cochran, and M. Wikelski. 2005. Biotelemetry of New World thrushes during migration: physiology, energetics and orientation in the wild. Integrative and Comparative Biology 45:295-304.

Brown, J. L. 1969. The buffer effect and productivity in tit populations. American Naturalist 103:347-354.

Buckland, S. T., D. R. Anderson, K. P. Burnham, J. L. Laake, D. L. Borchers, and L. Thomas. 2001. Introduction to distance sampling. Oxford University Press, New York, New York, USA.

Buler, J. J. 2006. Understanding habitat use by landbirds during migration along the Mississippi Gulf coast using a scaledependent approach. Dissertation. The University of Southern Mississippi, Hattiesburg, Mississippi, USA.

Burnham, K. P., and D. R. Anderson. 2002. Model selection and multimodel inference: a practical information-theoretic approach. Second edition. Springer-Verlag, New York, New York, USA.

Carpenter, F. L., M. A. Hixon, C. A. Beuchat, R. W. Russell, and D. C. Paton. 1993. Biphasic mass gain in migrant hummingbirds: body composition changes, torpor, and ecological significance. Ecology 74:1173-1182.

Chernetsov, N. 2006. Habitat selection by nocturnal passerine migrants en route: mechanisms and results. Journal of Ornithology 147:185-191.
Chernetsov, N., A. Mukhin, and P. Ktitorov. 2004. Contrasting spatial behaviour of two long-distance passerine migrants at spring stopovers. Avian Ecology and Behaviour 12:53-61.

Cimprich, D., M. S. Woodrey, and F. R. Moore. 2005. Passerine migrants respond to variation in predation risk during stopover. Animal Behaviour 69:1173-1179.

Cochran, W. W., and M. Wikelski. 2003. Individual migratory tactics of New World Catharus thrushes. Pages 274-289 in E. Sonnenschein, editor. Avian migration. Springer-Verlag, Berlin, Germany.

Cooper, R. J., and R. C. Whitmore. 1990. Arthropod sampling methods in ornithology. Pages 29-37 in M. L. Morrison, C. J. Ralph, J. Verner, and J. J. R. Jehl, editors. Avian foraging: theory, methodology and applications. Cooper Ornithological Society, Lawrence, Kansas, USA.

Cushman, S. A., and K. McGarigal. 2002. Hierarchical, multiscale decomposition of species-environment relationships. Landscape Ecology 17:637-646.

Davidar, P., and E. S. Morton. 1986. The relationship between fruit crop sizes and fruit removal rates by birds. Ecology 67: 262-265.

DeGraaf, R. M., and J. H. Rappole. 1995. Neotropical migratory birds: natural history, distribution, and population change. Cornell University Press, Ithaca, New York, USA.

Diehl, R. H., R. P. Larkin, and J. E. Black. 2003. Radar observations of bird migration over the Great Lakes. Auk 120:278-290.

Fahrig, L. 1997. Relative effects of habitat loss and fragmentation on population extinction. Journal of Wildlife Management 61:603-610.

Fahrig, L. 1998. When does fragmentation of breeding habitat affect population survival? Ecological Modelling 105:273292.

Fahrig, L. 2002. Effect of habitat fragmentation on the extinction threshold: a synthesis. Ecological Applications 12:346-353.

Farmer, A. H., and A. H. Parent. 1997. Effects of the landscape on shorebird movements at spring migration stopovers. Condor 99:698-707.

Farmer, A. H., and J. A. Wiens. 1998. Optimal migration schedules depend on the landscape and the physical environment: a dynamic modeling view. Journal of Avian Biology 29:405-415.

Forkner, R. E., and M. D. Hunter. 2000. What goes up must come down? Nutrient addition and predation pressure on oak herbivores. Ecology 81:1588-1600.

Futuyma, D. J., and F. Gould. 1979. Associations of plants and insects in a deciduous forest. Ecological Monographs 49:3350.

Gauthreaux, S. A. J. 1971. A radar and direct visual study of passerine spring migration in southern Louisiana. Auk 88: 343-365.

Gauthreaux, S. A., and C. G. Belser. 1999. Bird migration in the region of the Gulf of Mexico. Pages 1931-1947 in N. J. Adams and R. H. Slotow, editors. Proceedings of the 22nd International Ornithological Congress, Durban, South Africa. Birdlife South Africa, Johannesburg, South Africa.

Gustafson, E. J. 1998. Quantifying landscape spatial pattern: What is state of the art? Ecosystems 1:143-156.

Hedenström, A., and T. Alerstam. 1997. Optimum fuel loads in migratory birds: distinguishing between time and energy minimization. Journal of Theoretical Biology 189:227-234.

Heeremans, M. 1990. Can night migrants use interspecific song recognition to assess habitat? Le Gerfaut 80:141-148.

Holland, J. D., D. G. Bert, and L. Fahrig. 2004. Determining the spatial scale of species' response to habitat. BioScience $54: 227-233$.

Holland, J. D., L. Fahrig, and N. Cappuccino. 2005. Body size affects the spatial scale of habitat-beetle interactions. Oikos 110:101-108. 
Hurvich, C. M., and C.-L. Tsai. 1989. Regression and time series model selection in small samples. Biometrika 76:297307.

Hutto, R. L. 1985. Habitat selection by nonbreeding, migratory land birds. Pages 455-476 in M. L. Cody, editor. Habitat selection in birds. Academic Press, Orlando, Florida, USA.

James, F. C., and H. H. Shugart. 1970. A quantitative method of habitat description. Audubon Field Notes 24:727-735.

Jenni, L. 1996. Habitat selection of night-migrating passerines during ground fog. Journal für Ornithologie 137:425-434.

Jenni, L., and M. Schaub. 2003. Behavioural and physiological reactions to environmental variation in bird migration: a review. Pages 155-171 in P. Berthold, E. Gwinner, and E. Sonnenschein, editors. Avian migration. Springer-Verlag, Berlin, Germany.

Jenni-Eiermann, S. J., and L. Jenni. 1999. Habitat utilisation and energy storage in passerine birds during migratory stopover. Pages 803-818 in N. J. Adams and R. H. Slotow, editors. Proceedings of the 22nd International Ornithological Congress, Durban, South Africa. Birdlife South Africa, Johannesburg, South Africa.

Kotliar, N. B., and J. A. Wiens. 1990. Multiple scales of patchiness and patch structure: a hierarchical framework for the study of heterogeneity. Oikos 59:253-260.

Kuenzi, A. J., and F. R. Moore. 1991. Stopover of Neotropical landbird migrants on East Ship Island following trans-Gulf migration. Condor 93:869-883.

Lee, M., L. Fahrig, K. Freemark, and D. J. Currie. 2002. Importance of patch scale vs. landscape scale on selected forest birds. Oikos 96:110-118.

Letourneau, D. K., and L. A. Dyer. 1998. Experimental test in lowland tropical forest shows top-down effects through four trophic levels. Ecology 79:1678-1687.

Lichstein, J. W., T. R. Simons, and K. E. Franzreb. 2002. Landscape effects on breeding songbird abundance in managed forests. Ecological Applications 12:836-857.

Lindström, А. 1990. The role of predation risk in stopover habitat selection in migrating bramblings Fringilla montifringilla. Behavioral Ecology 1:102-106.

Loria, D. E., and F. R. Moore. 1990. Energy demands of migration on Red-eyed Vireos, Vireo olivaceus. Behavioral Ecology 1:24-35.

Lowery, G. H., Jr. 1945 Trans-Gulf migration of birds and the coastal hiatus. Wilson Bulletin 57:92-121.

Martin, G. R. 1990. The visual problems of nocturnal migration. Pages 187-197 in E. Gwinner, editor. Bird migration. Springer-Verlag, Berlin Germany.

Martin, T. E. 1980. Diversity and abundance of spring migratory birds using habitat islands on the Great Plains. Condor 82:430-439.

McCann, J. M., S. E. Mabey, L. J. Niles, C. Bartlett, and P. Kerlinger. 1993. A regional study of coastal migratory stopover habitat for Neotropical migrant songbirds: land management implications. Transactions of the North American Wildlife and Natural Resources Conference 58:398-407.

McCoy, J., and K. Johnston. 2000. Using ArcGIS spatial analyst. ESRI Publishing, Redlands, California, USA.

McGarigal, K., and W. C. McComb. 1995. Relationships between landscape structure and breeding birds in the Oregon coast range. Ecological Monographs 65:235-260.

Mitsch, W. J., J. R. Taylor, and K. B. Benson. 1991. Estimating primary productivity of forested wetland communities in different hydrologic landscapes. Landscape Ecology 5:75-92.

Moore, F. R. 1994. Resumption of feeding under risk of predation: effect of migratory condition. Animal Behavior 48:975-977.

Moore, F. R., and D. A. Aborn. 2000. Mechanisms of en route habitat selection: How do migrants make habitat decisions during stopover? Studies in Avian Biology 20:34-42.

Moore, F. R., S. A. J. Gauthreaux, P. Kerlinger, and T. R. Simons. 1995. Habitat requirements during migration: important link in conservation. Pages 121-144 in T. E. Martin and D. M. Finch, editors. Ecology and management of neotropical migratory birds. Oxford University Press, Oxford, UK.

Moore, F. R., and P. Kerlinger. 1987. Stopover and fat deposition by North American wood-warblers (Parulinae) following spring migration over the Gulf of Mexico. Oecologia 74:47-54.

Moore, F. R., P. Kerlinger, and T. R. Simons. 1990. Stopover on a Gulf Coast barrier island by spring trans-Gulf migrants. Wilson Bulletin 102:487-500.

Moore, F. R., and Y. Wang. 1991. Evidence of food-based competition among passerine migrants during stopover. Behavioral Ecology and Sociobiology 28:85-90.

Moore, F. R., M. S. Woodrey, J. J. Buler, S. Woltmann, and T. R. Simons. 2005. Understanding the stopover of migratory birds: a scale dependent approach. Pages 684-689 in C. J. Ralph and T. D. Rich, editors. Bird conservation implementation and integration in the Americas: Proceedings of the Third International Partners in Flight Conference, 20 24 March 2002. Pacific Southwest Research Station, USDA Forest Service General Technical Report PSW-191, Albany, California, USA.

Oksanen, L., S. D. Fretwell, J. Arruda, and P. Niemela. 1981. Exploitation ecosystems in gradients of primary productivity. American Naturalist 118:240-261.

O'Neill, R. V., D. L. DeAngelis, J. B. Waide, and T. F. H. Allen. 1986. A hierarchical concept of ecosystems. Princeton University Press, Princeton, New Jersey USA.

Parnell, J. F. 1969. Habitat relations of the Parulidae during spring migration. Auk 86:505-521.

Parrish, J. D. 1997. Patterns of frugivory and energetic condition in nearctic landbirds during autumn migration. Condor 99:681-697.

Parrish, J. D. 2000. Behavioral, energetic, and conservation implications of foraging plasticity during migration. Studies in Avian Biology 20:53-70.

Petit, D. R. 2000. Habitat use by landbirds along NearticNeotropical migration routes: implications for conservation of stopover habitats. Studies in Avian Biology 20:15-33.

Petit, L. J. 1999. Prothonotary Warbler. Pages 1-23 in A. Poole and F. Gill, editors. The birds of North America. Academy of Natural Sciences, Philadelphia, Pennsylvania and the American Ornithologists' Union, Washington, D.C., USA.

Rappole, J. H., and D. W. Warner. 1976. Relationships between behavior, physiology and weather in avian transients at a migration stopover site. Oecologia 26:193-212.

Rukke, B. A., and F. Midtgaard. 1998. The importance of scale and spatial variables for the fungivorous beetle Bolitophagus reticulatus (Coleoptera, Tenebrionidae) in a fragmented forest landscape. Ecography 21:561-572.

Saab, V. 1999. Importance of spatial scale to habitat use by breeding birds in riparian forests: a hierarchical analysis. Ecological Applications 9:135-151.

Simons, T. R., S. M. Peason, and F. R. Moore. 2000. Application of spatial models to the stopover ecology of trans-Gulf migrants. Studies in Avian Biology 20:4-14.

Skagen, S. K., J. F. Kelly, C. van Riper III, R. L. Hutto, D. M. Finch, D. J. Krueper, and C. P. Melcher. 2005. Geography of spring landbird migration through riparian habitats in southwestern North America. Condor 107:212-227.

Skagen, S. K., C. P. Melcher, W. H. Howe, and F. L. Knopf. 1998. Comparative use of riparian corridors and oases by migrating birds in southeast Arizona. Conservation Biology 12:896-909.

Sokal, R. R., and F. J. Rohlf. 1995. Biometry. Third edition. W. H. Freeman, New York, New York, USA.

Somershoe, S. G., and C. R. Chandler. 2004. Use of oak hammocks by Neotropical migrant songbirds: the role of area and habitat. Wilson Bulletin 116:56-63. 
Spengler, T. J., P. L. Leberg, and J. W. C. Barrow. 1995 Comparison of condition indices in migratory passerines at a stopover site in coastal Louisiana. Condor 97:438-444.

Strong, A. M. 2000. Divergent foraging strategies of two Neotropical migrant warblers: implications for winter habitat use. Auk 117:381-392.

Thomas, L., J. L. Laake, S. Strindberg, F. F. C. Marques, S. T. Buckland, D. L. Borchers, D. R. Anderson, K. P. Burnham, S. L. Hedley, J. H. Pollard, J. R. B. Bishop, and T. A. Marques. 2005. Distance 5.0 Release Beta 4. Research Unit for Wildlife Population Assessment, University of St. Andrews, UK. 〈http://www.ruwpa.st-and.ac.uk/distance/〉

Tischendorf, L., and L. Fahrig. 2000. On the usage and measurement of landscape connectivity. Oikos 90:7-19.

Trzcinski, M. K., L. Fahrig, and G. Merriam. 1999. Independent effects of forest cover and fragmentation on the distribution of forest breeding birds. Ecological Applications 9:586-593.

Turcotte, W. H., and D. L. Watts. 1999. Birds of Mississippi. University of Mississippi Press, Jackson, Mississippi, USA. van Horne, B. 1983. Density as a misleading indicator of habitat quality. Journal of Wildlife Management 47:893-901.

Ware, S., C. Frost, and P. B. Doerr. 1993. Southern mixed hardwood forest, the former longleaf pine forest. Pages 447493 in W. H. Martin, S. G. Boyce, and A. C. Echternacht, editors. Biodiversity of the southeastern United States, lowland terrestrial communities. John Wiley, New York, New York, USA.

Watermolen, J. 2005. Hydrologic unit boundaries: National Atlas of the United States. 1:2,000,000. U.S. Geological Survey, Reston, Virginia, USA. 〈http://nationalatlas.gov/ atlasftp.html $\rangle$

Wiens, J. A. 1989. Spatial scaling in ecology. Functional Ecology 3:385-397.

Wiens, J. A., and B. T. Milne. 1989. Scaling of 'landscapes' in landscape ecology, or, landscape ecology from a beetle's perspective. Landscape Ecology 3:87-96.

Williams, G. G. 1950. The nature and causes of the 'coastal hiatus.' Wilson Bulletin 62:175-182.

\section{APPENDIX A}

List of Nearctic-Neotropical migrant land bird species detected during transect surveys (Ecological Archives E088-106-A1).

\section{APPENDIX B}

Partial regression plots of only those explanatory variable exhibiting effects ("effects" model) on the mean and coefficient of variation of Neotropical migrant density at transects during spring (Ecological Archives E088-106-A2).

\section{APPENDIX C}

Relative variable importance (effect size) of eight variables in explaining mean density by season and species (Ecological Archives E088-106-A3).

\section{APPENDIX D}

Relative variable importance (effect size) of eight variables in explaining coefficient of variation of densities by season and species (Ecological Archives E088-106-A4).

\section{APPENDIX E}

Partial regression plots of only those explanatory variable exhibiting effects ("effects" model) on the mean and coefficient of variation of insectivorous Neotropical migrant density at transects during autumn (Ecological Archives E088-106-A5).

\section{APPENDIX F}

Partial regression plots of only those explanatory variable exhibiting effects ("effects" model) on the mean and coefficient of variation of frugivorous Neotropical migrant density at transects during autumn (Ecological Archives E088-106-A6). 